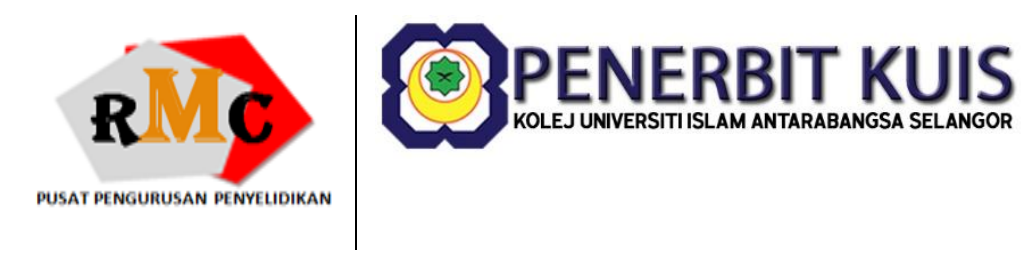

\title{
FAKTOR-FAKTOR PENDORONG PENGAMALAN NILAI-NILAI ISLAM DALAM KALANGAN PELAJAR MALAYSIAN AVIATION TRAINING ACADEMY (MATA), KUANTAN
}

Annasaii Bin Jamar

annasaii@kuis.edu.my

Fakulti Pendidikan

Kolej Universiti Islam Antarabangsa Selangor

\begin{abstract}
ABSTRAK
Ketegangan dalam kemelut moral dan akhlak dalam kalangan pelajar menjadi penyumbang kegagalan menterjemahkan nilai-nilai Islam dalam bentuk pengamalan dalam kehidupan seharian pelajar perlu dilaksanakan penilaian agar kefahaman dan pengamalan nilai Islam menjadi asas dalam kehidupan pelajar. Kajian ini bertujuan untuk mengenalpasti faktor-faktor pendorong pengamalan nilai-nilai Islam dalam kalangan pelajar di Malaysian Aviation Training Academy. Kajian ini berbentuk tinjauan dengan menggunakan soal selidik yang diadaptasi yang telah disahkan oleh dua orang pakar penilai dalam bidang pendidikan Islam yang berpengalaman dan mempunyai nilai kebolehpercayaan yang baik. Seramai 169 orang pelajar kursus lesen kejuruteraan penyelenggaran pesawat (cat B1.1) dan lesen juruteknik penyelenggaraan pesawat (cat A1.1) melalui teknik persampelan bertujuan-rawak mudah terlibat dalam kajian ini. Darjah kebolehpercayaan (alfa cronbach) bagi setiap persoalan kajian adalah 0.85 bagi aspek faktor ibu bapa, 0.79 bagi faktor media massa, 0.74 bagi faktor pensyarah dan 0.68 bagi faktor rakan sebaya. Data yang diperolehi dianalisis dengan menggunakan perisian SPSS (Statistical Package for Social Science, Version 20. Dapatan kajian mendapati faktor pensyarah merupakan faktor yang tertinggi dengan min 4.33, diikuti faktor ibu bapa 4.61, faktor rakan sebaya 3.65 dan media massa 4.50. Akhir sekali, Implikasi implikasi kajian ini menunjukkan bahawa penekanan aspek pengamalan ajaran Islam sangat
\end{abstract}


penting agar pelajar menjadi seorang muslim yang mengamalkan akhlak yang baik dalam kehidupan harian berlandaskan al-Quran dan as-Sunnah untuk membangunkan sahsiah pelajar yang baik.

Kata Kunci: Faktor pendorong, ibu bapa, media massa, pensyarah, rakan sebaya, pengamalan, nilai-nilai Islam

\section{ABSTRACT}

This study aims to identify the motivating factors for the practicing of Islamic values among students at the Malaysian Aviation Training Academy. Crisis in moral and moral turmoil among students is the contributor of failure to translate Islamic values in the form of practicing in the daily lives of students should be carried out assessment so that the understanding and practization of Islamic values becomes the basis for students' lives. This study is in the form of surveys using adapted questionnaires certified by two assessors in the field of Islamic education who are experienced and have good reliability value. A total of 169 students from aircraft maintenance engineering licence courses (CAT B1.1) and aircraft maintenance technician licenses (CAT A1.1) through sampling techniques were easily involved in this study. The degree of reliability (alpha cronbach) for each study question is 0.85 for parental factor aspects, 0.79 for mass media factors, 0.74 for lecturer factors and 0.68 for peer factors. The data was analyzed using SPSS (Statistical Package for Social Science, Version 20. The findings found that lecturers were the highest factor with mean 4.33 , followed by parental factors of 4.61, peer factor 3.65 and mass media 4.50. Finally, the implications of this study show that the emphasis on the practice of Islamic teaching is crucial so that students become a Muslim who practices good morals in everyday life based on the Quran and as-Sunnah to develop good student personality

Key words: Factor of impetus, parents, mass media, lecturer, peers, practicing, Islamic values.

\section{PENDAHULUAN}


Golongan pelajar terdiri dari kalangan remaja merupakan generasi yang menentukan masa hadapan sesebuah bangsa dan negara. Jatuh atau bangunnya sesebuah tamadun itu bergantung kepada potensi yang ada pada golongan pemuda dan pemudinya (Asmawati 2007). Namun hakikatnya, dunia hari ini memperlihatkan kepada kita betapa kritikalnya krisis keruntuhan akhlak dan meningkatnya gejala sosial dalam kalangan pelajar, khususnya remaja yang cukup membimbangkan.

Golongan sangat mudah terpengaruh kerana belum cukup usia kematangan mereka membuat pertimbangan dalan setiap perkara yang mereka lakukan. Mereka senang terjebak dan sering mengambil jalan mudah dalam perkara-perkara negatif yang merosakkan. Ini kerana menurut Azizi (2011), golongan pelajar dalam kajian ini membawa erti remaja yang berusia di antara 11 hingga 21 tahun, merupakan transisi antara zaman kanak-kanak dengan zaman dewasa yang melibatkan perubahan biologi, psikologi, sosial dan ekonomi serta melibatkan perubahan peringkat tidak matang ke peringkat matang.

Menurut Zainudin dan Norazmah (2011), pada masa kini, tingkah laku golongan pelajar dan remaja khususnya, semakin mencabar dengan pelbagai masalah yang membimbangkan. Peningkatan kadar gejala sosial yang merosakkan seperti penagihan dadah, perlakuan seks bebas, pembuangan bayi, kesalahan juvana dan sebagainya memberi gambaran bahawa betapa kroniknya masalah ini sekiranya tidak ditangani dengan segera. Kesan buruk berlakunya keruntuhan akhlak dan nilai moral ini pastinya melibatkan keluarga, masyarakat dan negara (Khairiah 2014). Oleh yang demikian, semua pihak seharusnya menggembleng tenaga untuk bersama-sama berusaha mencari penyelesaian dan memikirkan cara menangani permasalahan ini. 
Malek Bennabi (1986); Ma'rof (2003); Nooraini \& Salasiah (2013) menegaskan bahawa penglibatan remaja dalam pelbagai gejala sosial berpunca daripada beberapa faktor seperti faktor dalaman diri remaja itu sendiri dari aspek perkembangan personaliti, kegagalan fungsi institusi keluarga dan juga pengaruh rakan sebaya. Selain itu, Khairiah (2014) menambah bahawa cabaran globalisasi yang melanda masyarakat kita hari ini seperti pengaruh media cetak dan elektronik serta kemajuan sains dan teknologi dalam era dunia tanpa sempadan, telah memburukkan lagi keadaan kerana telah menjadikan sejumlah anggota masyarakat kita hilang jati diri dan mudah terpengaruh dengan gejala negatif yang merosakkan.

\section{MASALAH KAJIAN}

Ketegangan dalam kemelut moral dan akhlak dalam kalangan pelajar menjadi penyumbang kegagalan menterjemahkan nilai-nilai Islam dalam bentuk pengamalan dalam kehidupan seharian pelajar (Ahmad Munawar, 2009 \& Mohd Ashraf, 2010). Sebagai contoh, isu remaja tidak menunaikan solat dapat dilihat melalui dapatan kajian-kajian yang lepas dalam kalangan remaja (Hasna, 2012; Rahmat \& Mohd Toriq, 2013; Seri Kartini, 2013; Mohd Syukri et al., 2014; Siti Zaleha, 2014). Ini membuktikan bahawa tingkah laku remaja dalam pengamalan nilai-nilai Islam masih di tahap lemah. Menurut Syukri et al. (2014) segala kerosakan dan penyakit sosial yang menimpa golongan masyarakat terutama dalam kalangan remaja adalah kesan daripada sikap mereka yang sering meninggalkan solat dan tidak konsisten dalam menunaikan setiap hari. 
Tindak balas Ibu bapa dengan membina hubungan yang erat dalam membentuk tingkah laku remaja akan menghasilkan tingkah laku yang positif. Faktor ibu bapa merupakan cerminan tingkah laku dan akhlak remaja. Kajian (Ahmad Munawar, 2009; Dearana, 2010; Nur Dalilah, 2013) hubungan antara ibu bapa dan anak-anak dengan baik, berkualiti dan harmoni akan mempengaruhi contoh teladan yang baik dan meningkatkan keyakinan diri. Namun, sikap ibu bapa yang mengabaikan soal didikan agama, didikan yang kurang sempurna sedikit sebanyak menghakis jati diri serta memberi kesan yang negatif tingkah laku remaja (Ezhar et al. 2008 \& Svenson et al. 2012). Dapatan Khairul Hamimah (2008), remaja yang berpeleseran dan mengunjungi kelab malam merupakan mereka yang tinggal bersama keluarga. Indikasi ini menunjukkan rapuhnya institusi kekeluargaan. Justeru ikatan dan pertalian yang mesra yang bersifat keibubapaan diantara ibu bapa dan anak khususnya remaja menjadi benteng daripada pengaruh rakan sebaya yang menjurus kepada kerosakan nilai-nilai akhlak Islam (Paharudin Arbain et al., 2014).

Media massa merupakan alat menyebarkan informasi, pandangan, gosip dan persepsi kepada masyarakat. Malah, melalui media massa segala maklumat yang positif seperti menyebarkan ilmu mudah diperoleh. Namun, dari satu sudut media massa juga mempunyai nilai negatif sekiranya tidak dikawal agar tidak merosakkan remaja khususnya. Media massa menjadi agen kerosakan nilai moral dan akhlak sehingga hilang nilai-nilai Islam dalam kalangan remaja melalui intisari rancangan dan program media massa yang ditonjolkan. Hal ini diakui Buerah et al. (2012). Menurut Wan Norina et al. (2013) remaja menghabiskan masa lebih dari tiga jam untuk melayari laman sesawang 
yang bersantai. Tambahan lagi, dapatan Fariza (2010) remaja leka menghabiskan masa bersama media massa yang berbentuk hiburan. Implikasinya, pengaruh hiburan memberi keseronokan berlebihan berbanding wacana ilmu dan wacana agama. Hal ini akan mempengaruhi tingkah laku dalam pengamalan nilai-nilai Islam.

Faktor rakan sebaya sebenarnya tidak mencorakkan identiti dalam memberi galakan untuk mempengaruhi raka mereka kepada nilai Islam (Sarijah, 2007). Dapatan yang lalu, menterjemahkan melalui kajian mereka bahawa pengaruh hubungan rakan sebaya mempunyai perkaitan yang positif dan negatif (Zahrt \& Lenge, 2011; Albert \& Steinberg, 2011; Brechwald \& Prinstein, 2011). Terdapat kajian yang menyatakan pengaruh rakan sebaya memberikan lebih banyak pengaruh negatif, devian dan tindakan agresif berbanding positif (Zahrt \& Lenge, 2011; Albert \& Steinberg, 2011; Brechwald \& Prinstein, 2011). Kajian Tome et al. (2012) pengaruh rakan akan bertindak sebagai moderator untuk terlibat dalam perilaku kekerasan dan negatif. Pembentukan dan perkembangan tingkah laku remaja saling berkaitan rapat dengan nilainilai Islam dengan cerminan akhlak sama ada bersifat positif atau negatif. Ia juga mampu mengubah tingkah laku remaja sekali gus dengan perkembangan semasa.

\section{METODOLOGI KAJIAN}

Kajian ini berbentuk tinjauan dengan menggunakan soal selidik yang diadaptasi yang telah disahkan oleh dua orang pakar penilai dalam bidang pendidikan Islam yang berpengalaman dan mempunyai nilai kebolehpercayaan yang baik (Cresswell, 2014). Seramai 169 orang 
pelajar dari kursus lesen kejuruteraan penyelenggaraan pesawat dan lesen juruteknik penyelenggaraan pesawat melalui teknik persampelan rawak mudah terlibat dalam kajian ini (Othman Talib, 2013). Instrumen kajian ini terdiri daripada soal selidik yang telah diadaptasi daripada kajian Ashraf Che Soh (2010) dan Sri Kartika, (2013)

Nilai kebolehpercayaan Cronbach Alfa sebanyak adalah 0.85 bagi aspek faktor ibu bapa, 0.79 bagi faktor media massa, 0.74 bagi faktor pensyarah dan 0.68 bagi faktor rakan sebaya yang dianggap nilai yang sangat baik (Nunnally, 1978). Data kajian ini dianalisis secara statistik deskriptif iaitu frekuensi, min (M) dan sisihan piawai (SD) dan perastusan dengan menggunakan perisian pengaturcaraan "IBM SPSS Statistics". Interpretasi tahap kefahaman dan pengamalan pelajar dalam kajian ini dilakukan berdasarkan tiga tahap seperti yang ditunjukkan pada Jadual 3.1.

Jadual 3.1: Interpretasi skor min faktor pendorong pengamalan nilai Islam dalam kalangan

\begin{tabular}{|c|c|}
\hline Skor Min & Tahap \\
\hline $1.00-2.33$ & Rendah \\
\hline $2.34-3.66$ & Sederhana \\
\hline $3.67-5.00$ & Tinggi \\
\hline
\end{tabular}

Sumber : Rudzi Munap (2003)

\section{TINJAUAN LITERATUR}




\subsection{MASALAH PENGAMALAN NILAI ISLAM DALAM KALANGAN PELAJAR.}

Umum mengetahui bahawa pelajar-pelajar yang masih belajar termasuk dalam kategori remaja yang sedang meningkat dewasa. Remaja sering dikaitkan dengan masalah walaupun daripada sifat semula jadi, remaja adalah zaman yang penuh bertenaga dan mempunyai potensi diri yang cemerlang. Masalah sosial dan jenayah yang membabitkan remaja hari ini benar-benar membimbangkan. Ketidakupayaan dan kegagalan mengatasi halangan ini menimbulkan pelbagai masalah. Alam remaja dikatakan sebagai saat yang rapuh kerana pada peringkat ini mereka terdedah kepada pelbagai pengaruh serta tekanan luar yang kebanyakannya menjerumuskan kepada perkara negatif.

Isu keruntuhan akhlak dalam kalangan remaja di negara kita dicatatkan mengalami peningkatan dan sering dibincangkan dalam media sosial. Berdasarkan laporan Buerah et al. (2015), jumlah pelajar sekolah rendah dan menengah yang terlibat dengan masalah delinkuen dilaporkan seramai 108,650 orang daripada 5.3 juta orang pelajar. 18,550 pelajar didapati terlibat dalam salah laku ponteng sekolah sekaligus penyumbang terbesar dalam perangkaan jumlah salah laku diikuti dengan salah laku yang lain seperti buli, bergaduh, memukul dan lain-lain lagi. Senario ini amat membimbangkan dan jika tidak diambil perhatian lebih serius, dikhuatiri skala pelajar yang terlibat dengan isu-isu delinkuen ini akan semakin meningkat dan menjadi lebih parah.

Menurut Najati (1993), keruntuhan nilai akhlak dalam sesebuah masyarakat boleh menjadi ancaman kepada kesejahteraan mental individu. Ini turut disokong oleh Malek Bennabi (1998) yang 
menyatakan bahawa keruntuhan nilai akhlak turut menjadi punca sebenar kepada kemusnahan kerana keruntuhan nilai akhlak akan melemahkan setiap sendi sesebuah masyarakat. Remaja dengan mudahnya hilang jati diri dan mudah terjebak dalam kancah permasalahan sosial kesan dunia tanpa sempadan yang tidak dapat dielakkan. Abd. Rahim, Sufean \& Che Hassan (2006) telah menggariskan beberapa faktor pendorong keterlibatan remaja dalam gejala sosial yang merosakkan antaranya disebabkan oleh perkembangan personaliti remaja, pengaruh rakan sebaya dan juga kegagalan fungsi institusi keluarga.

Aspek penghayatan agama dalam diri remaja juga sangat memainkan peranan penting dalam membendung masalah sosial daripada semakin membarah. Kajian Yahya (2004) menunjukkan bahawa penghayatan akidah dalam kalangan pelajar yang lemah menyebabkan mereka terlibat dalam gejala black metal serta perkara-perkara yang meruntuhkan akhlak. Bahkan Yusuf al-Qardhawi (2012) juga menjelaskan bahawa kekuatan akidah dan hubungan yang berterusan dengan Allah SWT dapat mengatasi masalah kemerosotan akhlak para pelajar. Apabila berbicara tentang soal akidah dan akhlak, tidak dapat tidak remaja perlu memahani ilmu yang menjadi sumber panduan yang jelas seterusnya membuktikan dengan pengamalan apa yang telah diwahyukan oleh Allah SWT dan diwariskan oleh Nabi Muhammad SAW kepada umatnya sehingga ke hari kiamat nanti.

\subsection{PENGAMALAN BERASASKAN TEORI AL-GHAZALI}

Pendidikan Islam yang diajarkan kepada para pelajar di Malaysia bukan hanya sekadar perpindahan ilmu dari seorang guru kepada pelajar. Ianya bertujuan supaya ilmu yang disampaikan dapat diamalkan di dalam 
kehidupan. Terutama sekali pembelajaran berkaitan dengan kefahaman tentang ajaran Islam. Berkaitan perkara ini, teori al-Ghazali (1993) secara jelas menunjukkan berkaitan dengan ilmu yang dipelajari, mestilah diamalkan dengan baik.

Menurut Wan Mohd Nor (1989) bahawa ilmu yang dipelajari sepatutnya diikuti dengan amal soleh yang membawa kepada ketakwaan kepada Allah S.W.T. Ini menunjukkan bahawa persepsi pengetahuan yang baik berkaitan solat sepatutnya disusuli dengan tahap amalan solat yang memuaskan di kalangan pelajar. Maka, sepatutnya pembelajaran yang diikuti oleh para pelajar di sekolah diharapkan dapat melahirkan insan yang soleh dalam erti kata beramal dengan ilmu yang diperoleh.

Hasilnya, kesepaduan ilmu dan amal dapat diterjemahkan dengan baik. Berkaitan dengan teori ini Al-Ghazali (1993), turut mengaitkan dengan tujuan menuntut ilmu. Beliau menyebut bahawa nafsu sangat mencintai sesuatu yang dilarang di dalam agama. Terutama bagi penuntut ilmu yang mencari ilmu dengan tujuan untuk mendapat kedudukan, menonjolkan kehebatan diri serta mengumpulkan kesenangan dunia semata-mata.

Imam Al-Ghazali (1998) juga menambah berkaitan dengan konsep ilmu dan amal bahawa, perkataan dan perbuatan yang dilakukan mestilah sesuai dengan syarak. Beliau juga menambah bahawa ilmu dan amal yang tidak sesuai dengan syarak adalah sia-sia. Berkaitan dengan perkara ini, Imam Al-Ghazali (1998) telah membahagikan konsep ilmu kepada ilmu yang bermanfaat dan juga ilmu yang tidak bermanfaat. Seseorang yang menuntut ilmu mestilah menjaga dan memelihara daripada menuntut ilmu yang bercanggah dengan syarak. Al-Ghazali (1998) 
menyebut bahawa antara ilmu yang tidak terpuji adalah sihir dan talasim (tangkal dan azimat).

Kedua-duanya menimbulkan pelbagai bahaya. Teori ilmu dan amal yang diketengahkan oleh Al-Ghazali (1993) ini mengetengahkan kesepaduan ilmu iaitu gabungan di antara ilmu, amal dan iman. Ketigatiga konsep ini diperlukan supaya ilmu yang dipelajari dapat diamalkan dengan baik. Mengikut beberapa karya Imam al-Ghazali (1993) beliau menyatakan dengan jelas bahawa ilmu yang bermanfaat adalah ilmu yang mampu mendekatkan diri kepada Allah S.W.T.

Merujuk kepada kajian yang dijalankan ini, tahap pengamalan yang dipelajari oleh pelajar bermula dari seawal bangku sekolah mestilah disusuli oleh perlaksanaan yang sempurna. Oleh yang demikian, pelajar mestilah mengetahui mengenai kepentingan dan kewajipan yang merupakan suatu kefarduan ke atas diri mereka. Diharapkan kefahaman yang dimiliki mampu menjadikan mereka mengamalkan nilai Islam secara istiqamah di dalam kehidupan.

\subsection{NILAI-NILAI ISLAM}

Nilai bermaksud kualiti, mutu, taraf dan sifat ketinggian dari sudut pemikiran, agama dan kemasyarakatan (Kamus Dewan,1994). Istilah nilai boleh difahami dalam tiga konteks besar, iaitu kuantitatif, sifat dan aksiologi (Zdzislaw Najder 1975). Dalam bahasa Inggeris nilai diungkapkan dengan istilah value (Oxford Advanced Learner's Dictionary, 1994), kerana ia sering dikaitkan dengan apa yang perlu ada di dalam jiwa manusia. Nilai ialah sesuatu yang abstrak Ahmad Atory Hussain (1986), yang terdapat dalam sanubari manusia dan terjelma pada 
sistem sosial (Neil J. Smelser dan Paul B. Batles 2001). Abstrak di sini bermaksud tidak dapat dilihat, dipegang dan tidak boleh dirasai oleh manusia (Atory 1986). Nilai yang terdapat pada seseorang terbina melalui faktor dan situasi yang pelbagai di sepanjang proses kehidupan yang dilalui oleh individu (Wan Sabri Wan Hussin 2002).

Nilai juga diistilahkan sebagai moral (Ghazali Darusalam 2001), tetapi tidak semua moral itu mempunyai nilai (Abdul Rahman Md. Aroff 1999),. Sesuatu perlakuan yang baik dianggap sebagai bermoral sekiranya mendapat pengiktirafan daripada orang lain. Ini disebabkan moral mementingkan hubungan sesama manusia serta berdasarkan sentimen masyarakat setempat Ghazali Darusalam (2001), contohnya terdapat sebuah masyarakat yang menganggap arak adalah baik untuk tujuan memanaskan badan di negara-negara sejuk dan pengambilannya tidak salah. Maka ia dianggap perbuatan yang bermoral.

Ini berbeza dengan negara-negara Islam dan agama Islam itu sendiri kerana arak itu diharamkan (Abdullah Basmieh, 2010; 16:67; 2:219; $4: 43$; 5:90) walaupun ada yang beranggapan arak itu mempunyai 'manfaat' tersendiri (Abdullah Basmieh, 2010; 2:219). Nilai dari perspektif Islam merangkumi keseluruhan aspek kehidupan insan, termasuklah kedudukan, sosial, jawatan, pendidikan, pentadbiran, politik, ekonomi, kebudayaan dan seterusnya kepada hubungan antarabangsa (Al-Mu'jam al-Wasīt 1973),. Tonggak kepada segala nilai Muslim adalah berpusat kepada akidah dan syariat berlandaskan kepada suruhan Allah sebagaimana ikrar mereka di dalam solat yang bermaksud: "bawasanya solatku, tingkah lakuku, hidupku dan matiku adalah semata-mata kerana Allah sekalian alam Al-Qur'an (Abdullah Basmieh, 2010; 6:162) 
Antara peranan nilai-nilai Islam dalam kehidupan ialah: amanah berperanan menghindarkan pelajar daripada melanggar larangan dan suruhan Allah. Sifat amanah akan melahirkan sikap yang jujur, berhemat, cermat, jimat, tidak membazir, tidak mencuri, merompak dan melakukan segala bentuk penyeludupan dan penyelewengan. Malah mereka akan merasa malu kepada Allah apabila melakukan segala perbuatan yang tidak jujur. Nilai tanggungjawab akan membentuk pelajar yang sentiasa memperkukuhkan iman kepada Allah dengan melakukan kebaikan dan menjauhi kemungkaran. Ini akan melahirkan banduanita yang mempunyai misi, objektif dan matlamat dalam kehidupan dengan merancang dan melaksanakan tugasan yang dipertanggungjawabkan ke atasnya. Jiwa mereka akan berani mempertahankan kebenaran kerana Allah.

Kesimpulannya, peranan nilai-nilai Islam seperti yang dinyatakan di atas dapat menanam semangat mencintai kebaikan dan membuang sifat buruk yang terdapat dalam diri pelajar. Sikap amanah akan menghindari tabiat bermegah dan 'ujub. Nilai syukur membuang hasad, bakhil dan takabur. Dengan ikhlas menghindari sombong dan riak. Dedikasi, tanggungjawab dan disiplin menghindari malas. Nilai tekun membuang sikap berlengah. Bersih menghindari sikap pengotor dan berbudi mulia membuang sikap pemarah dan panas baran. Transformasi sikap ini akan mewujudkan suasana hidup yang lebih bertanggungjawab dalam menjalani kehidupan seharian pelajar.

\subsection{FAKTOR-FAKTOR PENDORONG}




\subsubsection{FAKTOR IBU BAPA}

Faktor keluarga merupakan asas pendidikan untuk mengamalkan nilainilai Islam seperti berakhlak terpuji. Menurut Ulwan (1989), Mohd Nasir (2005) \& Azhar (2006) suasana rumah tangga yang mengamalkan syiar Islam akan memudahkan pendidikan Islam anak-anak. Peranan ibu bapa sebagai ketua institusi kekeluargaan untuk mendidik perkara berkaitan akidah, amalan-amalan ibadah dan tingkah laku akhlak bermula dari peringkat kanak-kanak dan remaja. Menurut Zaleha Sulaiman (1995) ibu bapa bertanggungjawab meletakkan batu asas nilai-nilai Islam dan pembentukan konsep pembentukan diri yang positif dalam kalangan anak-anak.

Lain dari itu, ibu bapa merupakan ejen sosialisasi yang penting bagi anak-anak sebelum mereka dipengaruhi oleh ejen sosialisasi yang lain memungkinkan pengaruh yang negatif. Menurut Johari Talib (2007) pengaruh ibu bapa lebih kuat kerana jumlah masa anak-anak berada di rumah lebih panjang dari jumlah masa anak-anak berada di sekolah. Bagi mengelakkan remaja dari dipengaruhi budaya yang negatif, peranan ibu bapa amatlah ditagih agar institusi kekeluargaan mengamalkan nilai-nilai Islam terutamanya dalam pembentukan sahsiah cerminan Islam. Menurut Sofiah Samsudin dan Mohd. Fuad (2005) ibu bapa bertanggungjawab dalam proses pembinaan sahsiah sejak remaja dari alam sulbi memalui amalan-amalan yang berkaitan ibadah harian, panggilan nama yang baik. Oleh itu peranan ibu bapa memberikan pengalaman yang positif dan unik kepada anak-anak melalui kasih sayang, interaksi individu dan masyarakat.

\subsubsection{FAKTOR RAKAN SEBAYA}


Faktor rakan sebaya, adalah kuat dalam perkembangan remaja. Ini kerana kebanyakan masa mereka diluangkan bersama rakan berbanding ketika bersama ibu bapa (Ruzlan Md. Ali dan Rosna Awang Hashim 2003) sehingga menyebabkan mereka mudah terpengaruh dengan aktiviti dan perlakuan yang didorong oleh rakan sebaya.

Rakan sebaya menjadi tempat mereka berkongsi pengalaman, minat yang sama, serta dapat memberi sokongan moral saat memerlukan. Kenyataan ini disokong oleh Shahizan Hassan et al. (2003); Mohd Anuar Abdul Rahman dan Norshahril Abdul Hamid (2011) yang menjelaskan bahawa interaksi antara mereka dapat memberi peluang untuk menerima perbezaan pendapat masing-masing serta dapat meningkatkan pemahaman moral. Pada peringkat ini mereka mempunyai perasaan diterima dalam sesebuah kumpulan ataupun mereka cenderung untuk mengasingkan diri dan suka memberontak (Noran Fauziah Yaakub 2003).

Menurut Ismaiza Ismail (1999) dan Ghazali Othman (2003) remaja dari golongan tersebut mengharapkan agar dapat menyesuaikan diri serta diterima oleh rakan sebaya, sehingga ada yang terikut-ikut tingkah laku rakan sebaya mereka seperti cara berpakaian, cara bertutur, pergaulan, aktiviti seharian dan sebagainya. Ia disebabkan remaja terdedah kepada tekanan rakan sebaya (peer pressure) samada yang bersifat positif atau negatif (Shahizan Hassan et al. 2003).

Sekiranya remaja tersebut bergaul dengan rakan yang menekankan sifat-sifat positif, maka ia juga akan mengamalkan perkara kebaikan dan begitu juga sebaliknya. Rakan yang tidak mendorong ke arah mencapai 
kejayaan dunia dan akhirat hanya mendatangkan kemusnahan dalam diri remaja (Azizi Yahaya et al. 2012).

\subsubsection{FAKTOR MEDIA MASSA}

Teknologi media massa semakin pantas mengikut kemajuan arus permodenan kini di mana secara tidak langsung mempengaruhi sistem nilai masyarakat. Media massa terdiri daripada television, radio, filem, majalah, akhbar dan internet merupakan wahana informasi dan hiburan yang paling mudah diperolehi oleh segenap lapisan masyarakat. Suria Hani (2012) menjelaskan media memainkan peranan yang cukup besar bermula dari menambah ilmu pengetahuan, membentuk sikap, persepsi dan juga nilai kepercayaan. Ia juga membantu dalam menyesuaikan suatu tingkah laku dan nilai sesebuah kelompok masyarakat.

Islam memandang media sebagai salah satu medium dakwah dalam menyampaikan kebenaran dan memelihara kemaslahatan ummah (Marina Munira et al. 2011). Media yang mengandungi hiburan mestilah menepati syariat agama, tidak melalaikan daripada mengingati Allah, tidak mengandungi unsur-unsur maksiat ataupun tidak bermanfaat (Siti Suriani et al. 2011).

Azizi Yahaya et al. (2012) menyatakan bahwa unsur-unsur positif yang diketengahkan boleh membina pemikiran dan sahsiah yang baik dalam diri. Menurut Ahmad Kamil et al. (2011) paparan media yang didedahkan melalui media mudah mempengaruhi budaya dan pemikiran semua lapisan masyarakat terutamanya golongan remaja kini. menurut Azizi Yahaya et al. (2012) menyatakan bahawa pada peringkat remaja, mereka sedang mengalami proses perkembangan dan pencarian identiti 
diri sehingga mereka cenderung meniru dan mencuba perkara baru berdasarkan apa yang mereka saksikan.

\subsubsection{FAKTOR PENSYARAH}

Pensyarah atau guru merupakan individu bertanggungjawab dalam pembentukan sahsiah generasi muda akan datang yang berakhlak mulia dan sebahagian daripada agen perubahan dalam masyarakat. Memandangkan pendidikan di Malaysia yang sedang memasuki era pendidikan bertaraf dunia menyaksikan betapa pentingnya modal insan yang berkualiti tinggi, guru adalah role -model (Ab Halim Tamuri dan Mohd Khairul Azman 2010; Mohamad Khairi dan Asmawati Suhid 2010; Ab Halim Tamuri dan Noornajihan Jaafar 2012) yang dilihat sebagai faktor penting menjana kecemerlangan pendidikan negara Lantaran itu, tugas pensyarah bukan sekadar pemindah ilmu atau mudarris, bahkan berperanan sebagai muallim, muaddib, murabbi dan mursyid sebagaimana yang dituntut agama (Ab. Halim Tamuri dan Mohd Khairul Azman 2010; Ahmad Tarmizi dan Ab. Halim Tamuri \& Noornajihan Jaafar 2013; Ab. Halim Tamuri et al. 2012)

Maka, adalah diharapkan warga pendidik yang bakal mencorak generasi masa depan adalah dalam kalangan mereka yang terbina kemahiran insaniah dan tinggi jati diri hasil ibadah yang dihayati (Sumaiyah Sulaiman et al. 2012).

\section{DAPATAN KAJIAN}


Bahagian ini membincangkan dapatan kajian berdasarkan satu soalan kajian yang dinyatakan.

\subsection{PROFIL SAMPEL RESPONDEN}

Sampel kajian terdiri daripada 169 orang pelajar yang menuntut di Malaysian Aviaton Training Academy. Sebanyak 2 buah kursus terlibat sebagai sampel responden. Jadual 2 menunjukkan latar belakang sampel kajian yang terlibat secara lebih terperinci.

Jadual 5.1.1 Latar belakang demografi responden kajian

\begin{tabular}{|c|c|c|c|}
\hline $\begin{array}{c}\text { Latar } \\
\text { belakang } \\
\text { demografi }\end{array}$ & Item & Kekerapan & Peratusan \\
\hline \multirow{2}{*}{ Jantina } & Lelaki & 140 & 82.8 \\
\cline { 2 - 4 } & Perempuan & 29 & 17.2 \\
\hline \multirow{2}{*}{ Kursus } & $\begin{array}{c}\text { Lesen kejuruteraan } \\
\text { penyelenggaraan } \\
\text { pesawat (Cat B1.1) }\end{array}$ & 53 & 31.4 \\
\hline & $\begin{array}{c}\text { Lesen juruteknik } \\
\text { penyelenggaraan } \\
\text { pesawat (Cat A1.1) }\end{array}$ & 116 & 68.6 \\
\hline \multirow{2}{*}{$\begin{array}{c}\text { Tempat } \\
\text { tinggal }\end{array}$} & Bandaraya & 26 & 68.6 \\
\cline { 2 - 4 } & Bandar & 93 & 55 \\
\cline { 2 - 4 } & Luar bandar & 50 & 29.6 \\
\hline
\end{tabular}

Berdasarkan jadual 5.1.1, seramai 140 orang (82.8\%) pelajar lelaki dan 29 orang (17.2\%) pelajar perempuan yang mengikuti pembelajaran di Malaysian Aviation Training Academy (MATA). Dalam kajian ini, 53 orang (31.4\%) adalah pelajar yang menjalani program lesen jurutera penyelenggaraan pesawat dan $116(68.6 \%)$ adalah pelajar yang mengikuti program lesen juruteknik penyelenggaraan pesawat. Manakala, seramai 26 orang (15.4\%) peserta kajian berasal dari kawasan 
Bandaraya, 93 orang (55\%) peserta kajian berasal dari kawasan bandar dan 50 orang (29.6\%) peserta kajian berasal dari luar bandar.

\subsection{TAHAP FAKTOR-FAKTOR YANG MENDORONG PENGAMALAN NILAI ISLAM DALAM KALANGAN PELAJAR DI MALAYSIAN AVIATION TRAINING ACADEMY.}

Berdasarkan Jadual 5.2, tahap faktor-faktor yang mendorong pengamalan nilai Islam dalam kalangan remaja di Malaysian Aviation Training Academy Dapatan kajian menunjukkan faktor ibu bapa mencatatkan kekerapan min yang tertinggi sebagai faktor yang mendorong pelajar dalam pengamalan nilai Islam $(\min =4.61, \mathrm{sp}=0.69$ ) diikuti faktor media massa $(\min =4.50, \mathrm{sp}=0.44)$, faktor pensyarah $(\min =4.33, \mathrm{sp}=0.69)$ dan yang terakhir adalah faktor rakan sebaya $(\min =3.80, \mathrm{sp}=0.81)$.

\begin{tabular}{|l|c|c|c|}
\hline \multicolumn{4}{|c|}{$\begin{array}{l}\text { Jadual 5.2 Taburan skor min dan sisihan piawai faktor pendorong } \\
\text { pengamalan nilai Islam dalam kalangan pelajar. }\end{array}$} \\
\hline & Min & Sisihan Piawai & Interpretasi \\
\hline $\begin{array}{l}\text { Faktor } \\
\text { pensyarah }\end{array}$ & 4.33 & 0.59 & Tinggi \\
\hline $\begin{array}{l}\text { Faktor ibu } \\
\text { bapa }\end{array}$ & 4.61 & 0.69 & Tinggi \\
\hline $\begin{array}{l}\text { Faktor rakan } \\
\text { sebaya }\end{array}$ & 3.65 & 0.81 & Sederhana \\
\hline $\begin{array}{l}\text { Faktor media } \\
\text { massa }\end{array}$ & 4.50 & 0.44 & Tinggi \\
\hline
\end{tabular}




\section{PERBINCANGAN KAJIAN}

\subsection{FAKTOR PENSYARAH SEBAGAI PENDORONG PENGAMALAN NILAI ISLAM.}

Berdasarkan jadual 5.2, skor min bagi pensyarah mempunyai nilai 4.33 berada pada tahap tinggi. Ini menunjukkan responden bersetuju, pensyarah merupakan faktor pendorong dalam pengamalan nilai Islam. Dapatan kajian ini menyokong kajian Zawawi Temyati et al. (2011) menyatakan pendidik merupakan agen moral dan idola kepada pelajarpelajar. Hasil dapatan kajian ini selari kajian Ab Halim Tamuri dan Mohd Khairul Azman Ajuhary (2010); Ab Halim Tamuri dan Noornajihan Jaafar (2012); Mohamad Khairi Othman dan Asmawati Suhid (2010) bahawa segala perilaku, tindak tanduk, penampilan dan tutur kata seorang pensyarah menjadi teladan kepada pelajar dalam sedar atau tidak. Ini kerana masa mereka banyak dihabiskan dengan pensyarah. Maka jelaslah di sini bahawa keperibadian pensyarah mempunyai pengaruh besar kepada minda dan jiwa mahasiswa.

\subsection{FAKTOR IBU BAPA SEBAGAI PENDORONG PENGAMALAN NILAI ISLAM.}

Berdasarkan jadual 5.2, skor min bagi ibu bapa sebagai faktor pendorong mempunyai nilai yang paling tinggi dalam kajian ini. Dapatan ini menunjukkan pelajar bersetuju ibu bapa merupakan agen sosialisi dalam kelangsungan pengamalan nilai Islam dalam kehidupan mereka. Dapatan kajian ini selari dengan kajian Rohana Tan et al. (2016) bahawa contoh teladan yang baik daripada ibu bapa memberi kesan yang sangat besar kepada anak-anak. Anak-anak menghormati ibu bapa mereka dan patuh akan suruhannya selagi mana ia tidak bertentangan dengan Islam. Maka 
ibu bapa perlu memainkan peranan sebagai pembimbing atau kaunselor kepada anak-anak. Mereka bersedia memberikan nasihat ketika anak-anak menghadapi masalah. Dapatan dipersetujui oleh Naimah Ghazali et al. (2014) bahawa nasihat haruslah disampaikan dengan bijaksana supaya menarik perhatian dan tidak membosankan pendengar dalam mendidik jiwa anak-anak.

\subsection{FAKTOR RAKAN SEBAYA SEBAGAI PENDORONG PENGAMALAN NILAI ISLAM.}

Faktor pendorong yang seterusnya, rakan sebaya dengan nilai min yang sederhana 3.65. dapatan ini menunjukkan bahawa terdapat kelemahan dalam kalangan rakan sebaya sebagai agen pendorong mengamalkan nilai -nilai Islam dalam aspek pertuturan dan aspek pakaian. Dapatan ini selari dengan kajian Mohd Anuar et al. (2011), mendapati bahawa pelajar mudah terpengaruh dalam perbicaraan tutur kata dan pemakaian. Selain itu, dapatan kajian ini selari dengan dapatan kajian Rohana Tan et al. (2016) dalam aspek batas-batas pergaulan, pelajar masih gagal dalam menjaga batas pergaualan antara lelaki dan perempuan. Maka, pada peringkat ini pelajar mempunyai perasaan ingin tahu yang tinggi yang tinggi, sekali gus mendorong untuk mencuba melakukan perkara-perkara yang dilarang tanpa mengikut pertimbangan akal mereka.

\subsection{FAKTOR MEDIA MASSA SEBAGAI PENDORONG PENGAMALAN NILAI ISLAM.}

Faktor media massa memainkan peranan sebagai pendorong dalam pengamalan nilai Islam. Dengan nilai min 4.50, pelajar bersetuju bahawa media massa mampu menjadi ejen galakan dalam aspek pengamalan nilai 
Islam. Dapatan kajian ini selari dengan kajian yang dilakukan oleh Sharifah Nooraida Wan Hasan dan Sharifah Fatimah Wan Jamel (2011) menunjukkan bahawa bahan-bahan keagamaan dalam media massa mampu memberi pengetahuan dan kesedaran serta dihayati secara konsisten. Selain itu, dapatan kajian ini menyokong kajian yang dilakukan Wan Norina Wan Hamat et al. (2013) media massa yang berbentuk ilmiah merupakan antara kandungan media massa yang mampu menambah pengetahuan dan meningkatkan motivasi. Namun begitu dapatan kajian ini bercanggah dengan kajian yang dilakukan oleh Marina Munira et al. (2011) media massa lebih berfungsi ke arah hiburan sehingga meminggirkan nilai agama.

\section{KESIMPULAN}

Secara kesimpulannya, pengaruh persekitaran dalam kajian ini mampu mencorak keperibadian pelajar. Hal ini dapat membuktikan bahawa faktor-faktor pendorong pensyarah, ibu bapa, media massa dan rakan sebaya mampu membentuk peri laku dan sahsiah yang baik. Justeru, kajian ini memberi impak positif kepada pelajar dalam membangun jiwa mereka berdasarkan faktor-faktor persekitaran seperti dicadangkan dalam matlamat Pelan Pembangunan Pendidikan Malaysia 2013-2025 yang menggalakkan etika dan kerohanian, setiap mempunyai pegangan agama yang kuat dan mengamalkannya sebagai asas hidup, serta mendukung standard moral yang tinggi.

Implikasi kajian ini telah mencadangkan kepada ibu bapa perlu memperbaiki cara berkomunikasi dan perhubungan bersama anak-anak dengan mengambil berat akan keperluan dan kehendak mereka. Ini memberi kesan kepada tahap keyakinan dan penghargaan kendiri 
sekaligus mempengaruhi perkembangan mental dan membina sahsiah diri anak-anak. Ibu bapa juga perlu lebih prihatin dan mengawasi pergaulan anak-anak ketika bersama rakan sebaya serta peka akan pengaruh ataupun anasir-anasir Barat yang sukar dibendung kini. Selain itu, pensyarah atau guru merupakan agen paling penting dalam membentuk dan mendidik mahasiswa selain ibu bapa mereka. Maka pensyarah perlu menjadi rolemodel yang terbaik agar menjadi teladan dan ikutan para mahasiswa serta menanam nilai-nilai murni dalam diri mereka semasa ataupun di luar waktu pengajaran dan pembelajaran.

Sehubungan itu, faktor-faktor pendorong terhadap pengamalan nilai Islam yang melibatkan sampel kajian yang memfokuskan kepada aspek jantina, lokasi intitusi pengajian swasta yang lain dan faktor-faktor yang lain adalah dicadangkan sebagai kajian masa hadapan bagi mendapatkan suatu gambaran yang menyeluruh terhadap pelaksanaan model pengamalan nilai Islam dalam kalangan pelajar secara menyeluruh.

\section{RUJUKAN}

Ab. Halim Tamuri \& Mohd Khairul Azman Ajuhary. 2010. Amalan Pengajaran Guru Pendidikan Islam Berkesan Berteraskan Konsep Mu'allim. Journal of Islamic and Arabic Education 2 (1).

Ab. Halim Tamuri \& Noornajihan Jaafar. 2013. Hubungan antara Efikasi Kendiri dengan Kualiti Guru Pendidikan Islam Sekolah Menengah Kebangsaan Malaysia. Journal of Islamic and Arabic Education 5(1): Hlmn 41-60.

Ab. Halim Tamuri, Muhamad Faiz Ismail \& Kamarul Azmi Jasmi. 2012. Komponen Asas untuk Abd. Rahim Abd Rashid. 1993. KBSM: Pendidikan Nilai Merentasi Kurikulum. Kuala Lumpur: Dewan Bahasa dan Pustaka. 
Abd. Rahim Abd. Rashid, Sufean Hussin dan Che Hashim Hassan. 2006. Krisis \& Konflik Institusi Keluarga. Kuala Lumpur: Utusan Publication \& Distributors Sdn. Bhd.

Abdul Rahman Md. Aroff (1999), Pendidikan Moral: Teori Etika dan Amalan Moral, Selangor: Penerbit Universiti Putra Malaysia, h. 4.

Abdullah Basmeih. 2010. Tafsir Pimpinan Al- Rahman Kepada Pengertian Al- Quran. Edisi 14. Kuala Lumpur : Darul Fikri.

Ahmad Atory Hussain. 1986, Tingkah Laku Organisasi dalam Pengurusan Moden, Kuala Lumpur: Dewan Bahasa dan Pustaka, h. 113.

Ahmad Kamil, Mohd Fauzi Mohd Amin \& Mohd Shamsul Hakim. 2011. Matlamat dan Prinsip Media Islam. Dlm. Muhamad Zaki Mustafa, Ainurliza Mat Rahim, Zainol Abidin Ahmad \& Noor Adzrah Ramle. (pnyt) Representasi Islam dalam Media. Hlmn 13-26. Nilai: Universiti Sains Islam Malaysia.

Ahmad Munawar Ismail. 2009. Pengaruh Aqidah terhadap Penghayatan Akhlak Pelajar-Pelajar Sekolah Menengah Kebangsaan di Malaysia. Tesis Dr. Fal. Universiti Kebangsaan Malaysia.

Ahmad Tarmizi Abu Bakar \& Ab. Halim Tamuri. 2013. Guru Pendidikan Islam (GPI) sebagai Pendidik dan Daie Sepanjang Zaman: Satu Analisis. Prosiding Seminar Pertama Pendidikan dan Penyelidikan Islam (SePPIM'13). Hlmn 371-385. Fakulti Tamadun Islam. Universiti Teknologi Malaysia.

Albert, D., \& Steinberg, L. 2011. Peer Influences on Adolescent Risk Behavior. In M.T. Bardo, D. H. Fishbein, \& R. Milich (Eds.). Inhibitory Control and Drug Abuse Prevention: From Research to Translation. New York: Springer.

al-Ghazali, Abu Hamid Muhammad. 1993. Ayyuhal-Walad. Kaherah: Dar Al-Tawzi' Wa Al-Nasr Al-Islamiyyah.

al-Ghazali, Abu Hamid Muhammad. 1998. Ihya' Ulum Al- Din, J.5. Kaherah : Maktabah Misr. 
Al-Mu'jam al-Wasîț. 1973, Kaherah: Majma' al-Lughah al-'Arabiyyah, h. 577.

Asmawati Suhid. 2007. Pengajaran Adab \& Akhlak Islam dalam Membangunkan Modal Insan. MALIM: Jurnal Pengajian Umum Asia Tenggara. 8.pp. 167-178.

Azhar Ahmad. 2006. Strategi Pembelajaran Pengaturan Kendiri Pendidikan Islam dan Penghayatan Akhlak Pelajar Sekolah Menengah di Sarawak. Tesis Dr. Fal. Universiti Kebangsaan Malaysia.

Azizi Hj. Yahya. 2011. Definisi Remaja dan Pembentukan Konsep Kendiri Dalam Hubungannya dengan Keluarga. Universiti Teknologi Malaysia, Johor.

Azizi Yahaya, Shahrin Hashim, Yusof Boon, Jamaludin Ramli \& Nurul Ezzati Azizi. 2012. Penyelewengan Tingkah Laku Remaja Punca dan Rawatan. Penerbit Johor: UTM Press.

Brechwald, W. A. \& Prinstein, M. J. 2011. Beyond Homophily: A Decade of Advances in Understanding Peer Influence Processes. Journal of Research on Adolescence. 21(1): 166-179. doi: 10.1111/j.1532-7795. 2010.00721.x.

Buerah Tunggak, Maznah Ali, Nurafzan Muhamad \& Md. Hamzaimi Azrol Md Baharuddin. 2012. Delinkuensi Pelajar dan Cadangan Penyelesaiannya Menerusi Model Pembangunan Sahsiah Remaja/ Pelajar Muslim Bersepadu. Seminar Antarabangsa Perguruan\& Pendidikan Islam: Le Grandeur Palm Resort, Senai, Johor Baru. 0809 Mac 2012.

Buerah Tunggak, Shanah Ngadi \& Hamimah Abu Naim. 2015. Delinkuen Pelajar Dan Cadangan Penyelesaiannya Menerusi Model Pembangunan Sahsiah Remaja/Pelajar Muslim Bersepadu. Jurnal Hadhari. 7 (2): 11-30.

Creswell, John W. 2014. Research Design: Qualitative, Quantitative, and Mixed Methods Approaches. Thousand Oaks, California: SAGE Publications. 
Dearana Morshidi. 2010. Hubungan ibadah solat fardhu dan penghayatan akhlak pelajar: kajian di bahagian Miri, Sarawak. Tesis Sarjana. Fakulti Pendidikan. Universiti Kebangsaan Malaysia.

Ezhar, Tamam., Zamre Yaakob \& Mohamad Rezal Hamzah. 2008. Faktor penglibatan remaja daripada keluarga berpendapatan rendah di bandar dalam masalah sosial Jurnal Pembangunan Belia. Kementerian Belia dan Sukan Malaysia. 1 - 18.

Fariza,M.,S., \& Muhammad , F., A. 2010. Media Sebagai Tarikan Psikologi Dalam Dakwah.Kertas kerja Muzakarah Ulama' dan Cendiakawan Islam. Perak: Pejabat SUK Negeri Perak.

Ghazali Darusalam 2001, Kursus Tamadun Islam dan Pendidikan Moral: Nilai-nilai Moral dalam Pelbagai Aspek, Apresiasi Moral dan Badanbadan Dunia, Kuala Lumpur: Utusan Publications, h. 75

Ghazali Othman. 2003. Masalah Perkembangan Sosioemosi Remaja: Kaedah Penyelesaian. Dlm. Ruzlan Md. Ali et al. Perkembangan Sosioemosi Remaja: Tanggungjawab Bersama. Sintok: Penerbit Universiti Utara Malaysia.

Hasna Bidin. 2016. Pelaksanaan solat dalam kalangan pelajar muslim di Kolej Komuniti Bukit Beruang, Melaka. Tesis Sarjana Falsafah Fakuti Tamadun Islam.Univrsiti Teknologi Malaysia.

Ismaiza Ismail. 1999. Teknik Mendidik dan Memahami Jiwa Anak. Darul Nu'man. Kuala Lumpur.

Johari Talib. 2007. Pengaruh gaya keibubapaan terhadap pencapaian akademik kanakkanak. Dlm. Wacana Pengajian Umum, hlm. 77-94. Bangi: Universiti Kebangsaan Malaysia.

Kamus Dewan. 1994, ed. ke-3, Kuala Lumpur: Dewan Bahasa dan Pustaka, h. 930.

Khairiah Bte Sulaiman. 2014. Amalan-amalan islam dan kesannya terhadap pelajar aliran agama: kajian di Sekolah Menengah Agama. Kertas Projek Ijazah Sarjana Muda, Open University Malaysia.

Khairul Hamimah Binti Mohammad Jodi. 2008. Pemahaman Akidah Di Kalangan Pelajar Institut Pengajian Tinggi Swasta Dan Kesannya 
Terhadap Masalah Akhlak:Suatu kajian.Seminar Kebangsaan Kemahiran Insaniah \& Kesejahteraan Sosial 2008 pada 18-19 Ogos 2008, Melaka.

Ma'rof Redzuan. 2003. Psikologi Sosial. Serdang: Penerbit Universiti Putra Malaysia.

Malek Bennabi. 1998. On the Origins of Human Society. London : The Open Press, 1998.

Marina Munira Mutalib, Suhailiza Md. Hamdani, Khatijah Othman \& Roslizawati Mohd Ramli 2011. Tugas dan Tanggungjawab Media dalam Pembangunan Insan Dlm. Muhamad Zaki Mustafa, Ainurliza Mat Rahim, Zainol Abidin Ahmad \& Noor Adzrah Ramle. (pnyt) Representasi Islam dalam Media Universiti Sains Islam Malaysia, hlmn 41-52. Nilai: Universiti Sains Islam Malaysia.

Marina Munira Mutalib, Suhailiza Md. Hamdani, Khatijah Othman \& Roslizawati Mohd Ramli 2011. Tugas dan Tanggungjawab Media dalam Pembangunan Insan Dlm. Muhamad Zaki Mustafa, Ainurliza Mat Rahim, Zainol Abidin Ahmad \& Noor Adzrah Ramle. (pnyt) Representasi Islam dalam Media Universiti Sains Islam Malaysia, hlmn 41-52. Nilai: Universiti Sains Islam Malaysia.

Mohamad Khairi Othman \& Asmawati Suhid. 2010. Peranan Sekolah dan Guru dalam Pembangunan Nilai Pelajar Menerusi Penerapan Nilai Murni: Satu Sorotan. MALIM. SEA Journal of General Studies.

Mohd Anuar Abdul Rahman \& Norshahril Abdul Hamid. 2011. Kesan Persekitaran terhadap Pembangunan Emosi Pelajar di Fakulti Pendidikan, UTM. Journal of Education Psychology \& Counseling.

Mohd Ashraf Che Soh @ Yusoff. 2010. Pengamalan Nilai-Nilai Islam dalam Kalangan Pelajar di Sekolah Menengah Daerah Kota Kinabalu, Sabah. Tesis Sarjana. Universiti Kebangsaan Malaysia.

Mohd Nasir, O. 2005. Akhlak dan Kaunseling Islam. Kuala Lumpur: Utusan Publication \& Distributor Sdn Bhd

Naimah Ghazali, Khadijah Abdul Razak \& Maimun Aqsha Lubis. 2014. Metode Didikan Ibu Bapa dalam Pembentukan Akhlak Anak. 
Proceeding The Sixth International Conference And Workshop On Asean Studies In Islamic Culture And Educational

Najati, Muhammad Uthman. 1993. Al-Hadith al-Nabawiy wa 'Ilmu alNafs. Beirut : Dar al Syuruq.

Neil J. Smelser dan Paul B. Batles. 2001, International Encyclopedia of the Social and Behavioral Science, vol. 8, Amsterdam: Elsvier, h. 16151 .

Nooraini Othman \& Salasiah Khairollah. 2013. Explorasi Hubungan antara Personaliti Islamik dan Gaya Keibubapaan. International Journal of Islamic Thought. Vol. 4: (Dec.) 2013.

Noran Fauziah Yaakub. 2003. Perkembangan Sosial dan Emosi di Kalangan Remaja: Peranan Ibu bapa. Dlm Perkembangan Sosioemosi Remaja: Tanggungjawab Bersama. Jabatan Penerbitan dan Teknologi Media: Universiti Utara Malaysia.

Nur Dalilah Zakaria. 2013. Pelaksanaan ibadat solat dan hubungannya dengan konflik rumahtangga: Kajian di unit runding cara keluarga, bahagian perkahwinan dan pembangunan keluarga, Jawi. Jurnal Syariah, Jil.21, Bil. 2, Hal. 145-164, Jabatan Usul Fiqh:Universiti Malaya, Kuala Lumpur.

Othman Talib. 2013. Asas Penulisan Tesis Penyelidikan \& Statistik. Serdang: Penerbit Universiti Putra Malaysia.

Oxford Advanced Learner's Dictionary, ed. ke-7, New York: Oxford University Press, h. 1631-1632.

Paharudin Arbain, Misnan Jemali, Ibrahim Hashim \& Azmil Hashim. 2014. Persepsi Murid terhadap Pelaksanaan Kaedah Pengajaran Guru dan Hubungannya Dengan Pencapaian Murid Dalam Tilawah AlQuran. Jurnal Penyelidikan Dedikasi. Vol. 8.

Rahmat Abdullah \& Mohd Toriq Hj Sulaiman. 2013. Tahap Kefahaman dan Pelaksanaan Ibadat Solat Lima Waktu di kalangan Pelajar Muslim di Kolej Komuniti Selandar. Prosiding Seminar Penyelidikan. Kolej Komuniti Selandar, Melaka. 
Rudzi Munap, 2003. Penilaian Program Diploma Kesetiausahaan Eksekutif Di Universiti Teknologi Mara, Tesis Dok. Fal. Universiti Kebangsaan Malaysia.

Ruzlan Md. Ali \& Rosna Awang Hashim. 2003. Kanak-Kanak, Remaja dan Sosioemosi: Satu Sorotan Ringkas. Dlm Perkembangan Sosioemosi Remaja: Tanggungjawab Bersama. Sintok: Jabatan Penerbitan dan Teknologi Media Universiti Utara Malaysia.

Sarijah Abdul Salim. 2007. Faktor-faktor Pengamalan Nilai-Nilai Islam di Kalangan Pelajar: satu Kajian di Sekolah Menengah Daerah Jempol, Negeri Sembilan. Tesis Sarjana. Universiti Kebangsaan Malaysia.

Seri Kartini Jurami \& Fariza Md Sham. 2013. Pengamalan Ajaran Islam dalam Kalangan Pelajar Politeknik Ungku Omar, Ipoh. Islamiyyat 35(1.)

Shahizan Hassan, Tsai Chen Chien \& Saw Hooi Chin. 2003. Intrapersonal dan Interpersonal untuk Remaja. Pahang: PTS Publications \& Distributor Sdn. Bhd.

Sharifah Nooraida Wan Hasan \& Sharifah Fatimah Wan Jamel. 2011. Tinjauan Keperluan Aktiviti Kerohanian dalam Kalangan Guru Pelatih Muslimah di IPG Kampus Batu Lintang. Jurnal Penyelidikan IPG Kampus Batu Lintang, Jilid 10, 1-13.

Siti Suriani Othman, Lee Kuok Tiung, Rosliza Mohd Ramli \& Jaziratul Shila Jamal. 2011. Islam dan Hiburan dalam Media: Satu Dilema di Persimpangan. Dlm. Muhamad Zaki Mustafa, Ainurliza Mat Rahim, Zainol Abidin Ahmad dan Noor Adzrah Ramle. (pnyt) Representasi Islam dalam Media. Universiti Sains Islam Malaysia, hlmn 89-110. Nilai: Universiti Sains Islam Malaysia.

Siti Zaleha. 2014. Gaya Hidup remaja dan hubungannya dengan pengamalan Islam di bandar baru permas jaya, johor bahru. Tesis sarjana. Universiti kebangsaan malaysia.

Sumaiyah Sulaiman, Rahaila Omar, Mahawa Pilus \& Abd Rashid Zainal. 2012. Kefahaman, Pelaksanaan dan Penghayatan Solat Bakal Guru. Persidangan Kebangsaan Pendidikan Islam. Seremban. 
Suria Hani A. Rahman. 2012. Islamic and Cultural Identity in Media. Dlm Kepimpinan dan Pengurusan: Dakwah, Media dan Ilmu. Bangi: Penerbit UKM.

Svensson, Y. 2012. "Peer Selection and Influence of Delinquent Behavior of Immigrant and Non-Immigrant Youths: Does Context Matter?" dalam International Journal of Behavioral Development, 36(3), ms.178-185.

Syukri Ahmad, Yahya Don, Wan Abdul Rahman Khudri Wan Abdullah, Mohammed Ibrahim \& Shahril Fazli Mat Hussain. 2014. Penghayatan solat dan pengimarahan masjid: Kajian dalam kalangan pelajar Universiti Utara Malaysia.

Tomé, G., Matos, M. G., Simões, C., Camacho, I., \& Diniz, J. A. 2012. How Can Peer Group Influence the Behavior of Adolescents: Explanatory Model. Global Journal of Health Science. 4(2): 26-35. doi:10.5539/ gjhs. V 4n2p26.

Ulwan. A.N. 2012. Pendidikan Anak Dalam Islam. Jawa Tengah: Penerbit Insan Kamil.

Wan Mohd Nor Wan Daud. 1989. Konsep Ilmu Dalam Islam. Pulau Pinang .Sinaran Bros Sdn Bhd.

Wan Norina W.H.,Zaharah,H.,Ahmad, F.,Mohamed ,Y., \& Ahmad Arifin,S.(2013). Pengaruh Media Massa Terhadap Penampilan Akhlak Pelajar Islam Politeknik Malaysia. The Online Journal of Islamic Education. Januari 2013, Vol.1, Issue 1.

Wan Sabri Wan Hussin. 2002, "Nilai dan Etika Islam dalam Perniagaan: Amalan dan Tanggapan Masyarakat Malaysia", Tesis Kedoktoran, Institut Pengajian Siswazah dan Penyelidikan, Universiti Malaya, h. 114.

Yahya Ibrahim. 2004. Etiologi Masalah Sosial: Kajian terhadap Remaja di Sungai Petani, Kedah. Jurnal Psikologi dan Pembangunan Manusia. 2004. 20: 47-66. 
Yusuf al-Qardhawi. 2012. Ciri-ciri Unggul Masyarakat Islam yang Kita Idamkan. Terj. Ustaz Mohamaz Zaini Yahaya. Penerbitan Seribu Dinar.

Zahrt, D. M. \& Lange, M. D. 2011. Aggressive Behavior in Children and Adolescents. Pediatrics in Review. 32, 325, doi: 10.1542/pir.32-8325.

Zainudin Sharif \& Norazmah Mohamad Roslan. 2011. Faktor-Faktor yang Mempengaruhi Remaja Terlibat dalam Masalah Sosial Di Sekolah Tunas Bakti, Sungai Lereh, Melaka. Journal of Education Psychology \& Counseling. 1: 115-140.

Zaleha Sulaiman. 1995. Pengurusan Pencapaian Akademik Pelajar Sekolah Menengah di Luar Bandar: Kes Empat Buah Sekolah Menengah di Negeri Kedah Darul Aman. Tesis Sarjana. Kedah: Universiti Utara Malaysia.

Zawawi Temyati, Khadijah Abdul Razak \& S. Salahudin Suyurno. 2011. Falsafah Pendidikan Islam Melahirkan Insan Berakhlak. Proceedings of 2nd International Conference on Islamic Education 2011 (ICIEd 2011). Selangor: Association of Malaysian Muslim Intellectuals.

Zdzislaw Najder. 1975. Values and Evaluation, Oxford: Clarendon Press, h. 42 . 